\title{
El episodio de Manuel de Sosa Coitiño: ¿un cuento de amor, de locura y de muerte?
}

\author{
OFEK KEHILA*
}

\begin{abstract}
Resumen
Este artículo desea incursionar en la poética de subversión que caracteriza la construcción de personajes en la obra cervantina, y ello a partir del análisis del episodio de Manuel de Sosa Coitiño en el Persiles. El estudio examina dos procesos paralelos e interrelacionados a los que el soldado portugués fue sometido: la deificación de su novia Leonora y el proceso de su construcción a partir del estereotipo del enamorado portugués. Según intentaremos demostrar, Cervantes ha creado un personaje cuyos rasgos estereotípicos se ven desestabilizados en el contexto del episodio. El examen de dicho fenómeno podría esclarecer la actitud crítica del autor ante uno de los tópicos más populares de las letras del Siglo de Oro español.
\end{abstract}

Palabras clave: Cervantes; Persiles; Manuel de Sosa Coitiño; tópicos; estereotipo; enamorado portugués.

Title: The episode of Manuel de Sosa Coitiño: a story of love, madness and death?

\begin{abstract}
This article seeks to explore the poetics of subversion inscribed in the construction of characters in Cervantes' works, via the analysis of Manuel de Sosa Coitiño's episode in the Persiles. The study examines two parallel and interrelated processes that the Portuguese soldier underwent: the deification of his fiancée Leonora and the process of his construction as the stereotype of the Portuguese lover. We will show how Cervantes crafted the episode in a manner that leads to the destabilization of the stereotypical features of his character. An examination of this phenomenon could offer insight into the author's critical attitude towards one of the most popular literary clichés of the Spanish Golden Age.
\end{abstract}

* Universidad Hebrea de Jerusalén. ofek.kehila@mail.huji.ac.il / ORCID iD: https://orcid. org/0000-0001-6664-7032. 
Keywords: Cervantes; Persiles; Manuel de Sosa Coitiño; Clichés; Stereotype; The Portuguese Lover.

\section{Cómo citar este artículo / Citation}

Kehila, Ofek (2019). «El episodio de Manuel de Sosa Coitiño: ¿un cuento de amor, de locura y de muerte?», Anales Cervantinos. 51, pp. 179-196, https://doi.org/10.3989/ anacervantinos.2019.009.

La obra cervantina cobija una variedad de personajes tópicos que se obstinan en transgredir los límites de su tipificación. Pensemos en don Quijote, el cual, siendo caracterizado a lo largo de la novela como un hidalgo loco y delirante, logra revelarse una y otra vez como un ser racional y consciente de sus actos (Azar 1998); o en la bárbara Ricla, quien pese a su supuesto salvajismo sale en auxilio de Antonio con un verdadero espíritu de caridad (Armstrong-Roche 2011); o en Preciosa, cuya conducta desafía abiertamente la malévola caracterización inicial de los gitanos emitida por la voz narrativa de La Gitanilla. Cervantes parece empeñarse en reconstruir en sus textos una serie de estereotipos históricos, literarios y sociales para cuestionarlos después. ¿Cuál es el sentido de esta peculiar configuración? ¿Cuál sería la intentio operis de este comportamiento identificable en la obra cervantina? El presente estudio procurará responder estas preguntas a partir del análisis del episodio de Manuel de Sosa Coitiño, «el enamorado portugués» (Los trabajos de Persiles y Sigismunda: I, 9-11; III, 1) ${ }^{1}$.

El episodio del enamorado portugués en el Persiles está constituido por dos partes: en la primera, el portugués relata el suceso de su casamiento frustrado con Leonora, muriendo en el acto de concluir su historia; en la segunda, los protagonistas de la obra visitan su falsa sepultura en Lisboa, leen la inscripción sepulcral, y se enteran de la muerte de Leonora. En el mencionado epitafio se lee que el soldado portugués murió de amor; no obstante, una lectura atenta del episodio conducirá a una conclusión diferente.

Mi trabajo examinará dos procesos paralelos e interrelacionados a los que el soldado portugués fue sometido: el proceso de deificación de su novia, que terminó con su locura y muerte, y el proceso de su caracterización desde el prisma del lugar común del enamorado portugués, que culmina con el epitafio de su sepultura en Lisboa. El análisis intentará demostrar que mientras que los múltiples constructores de Sosa obran con el objetivo de encerrarlo dentro de un estereotipo, hay algo en él que rechaza dicha categorización.

En el capítulo I, 9, del Persiles nos encontramos con Manuel de Sosa Coitiño, un soldado portugués que estaba preso en la cárcel de los bárbaros y se fugó de la isla durante el gran incendio, junto con los protagonistas de 
la obra. En el curso de un viaje marítimo entre las islas desoladas, Periandro y Auristela notan su canto desde una de las barcas y lo invitan a la suya. Al desembarcar en tierra firme, Periandro insta al portugués a que relate a los presentes su historia. Sosa acepta y comienza su narración en el capítulo que sigue, el capítulo diez.

Según cuenta el soldado, sus desgracias empezaron el día en que vio por primera vez a Leonora Pereira, una de las doncellas más ricas, hermosas y deseadas en todo el reino de Portugal. Sosa, quien era vecino de los Pereira, pasaba su tiempo adorándola de lejos y terminó pidiéndola en matrimonio a su padre. Este le replicó que Leonora todavía no tenía la edad de casarse y que habría que esperar dos años. Confiando en la promesa del padre de darle a su hija por esposa, el soldado parte a Berbería para ocupar un cargo militar de suma importancia y al término de dos años regresa a su patria. En Lisboa, alguien, no se sabe quién, le avisa que Leonora le será entregada dentro de pocos días en un monasterio llamado la Madre de Dios. Sosa casi muere de felicidad y empieza a prepararse para la boda.

El día de la boda es descrito por el soldado a la manera de un desposorio real: el monasterio adornado, los invitados de la nobleza, la música que resuena en el aire y la novia, Leonora, acompañada por las monjas y vestida como una princesa:

En esto salió por la puerta del claustro la sin par Leonora, acompañada de
la priora y de otras muchas monjas, vestida de raso blanco acuchillado, con
saya entera a lo castellano, tomadas las cuchilladas con ricas y gruesas
perlas. Venía forrada la saya en tela de oro verde; traía los cabellos sueltos
por las espaldas, tan rubios, que deslumbraban los del sol y, tan luengos,
que casi besaban la tierra; la cintura, collar y anillos que traía, opiniones
hubo que valían un reino. Torno a decir que salió tan bella, tan costosa, tan
gallarda y tan ricamente compuesta y adornada, que causó invidia en las
mujeres y admiración en los hombres (Cervantes 2004: 203) ${ }^{2}$.

En el centro de la iglesia han situado una especie de tribuna que el texto denomina «teatro» (volveré más tarde a este empleo particular de la palabra). A dicho «teatro» sube primero la novia Leonora y después el novio Manuel. La multitud de invitados alza su voz deseándoles felices y largos años, gesto que resultará más que irónico a la luz de lo que ocurrirá después.

A esta altura sucede algo impensable. Leonora toma la mano de su novio y en lugar de seguir con la ceremonia del casamiento, admite que lo ha engañado: no se casará con él sino que tomará los hábitos y se convertirá en monja.

Yo, señor mío, soy casada y en ninguna manera, siendo mi esposo vivo, puedo casarme con otro. Yo no os dejo por ningún hombre de la tierra, sino

2. A partir de aquí, las citas del Persiles corresponden a esta edición y solo se indicarán las páginas. 
por uno del cielo, que es Jesucristo, Dios y hombre verdadero [...] Si esto os parece traición o descomedido trato, dadme la pena que quisiéredes y el nombre que se os antojare, que no habrá muerte, promesa o amenaza que me aparte del crucificado esposo mío (204-205).

En cuanto Leonora deja de hablar, las monjas la desnudan y cortan sus cabellos. Sosa, estupefacto ante este desarrollo de los hechos, cae de rodillas y por poco rompe en llanto. Luego se alza, emite las palabras Maria optimam partem elegit de Lucas $(10,41-42)$, que significan «María escogió la buena parte», baja del «teatro» y vuelve a su casa, donde pensando incesantemente en lo ocurrido aquel día, casi enloquece.

La historia y la vida de Manuel de Sosa Coitiño parecen acabar al mismo tiempo: las últimas palabras de aquel capítulo describen al soldado muriendo en el acto de dar término a su relato, y las primeras del capítulo siguiente pintan la escena de su entierro en el suelo nevado de la isla. Más aún, el mismo Sosa había anticipado este doble final al principio de su discurso ${ }^{3}$. Pero lo cierto es que su historia sobrevive a su muerte.

El tercer libro del Persiles se abre con la llegada de los protagonistas al reino de Portugal. En Lisboa, Periandro se encuentra con un portugués que afirma que es uno de los sobrevivientes de la isla bárbara. Este le cuenta a Periandro que había sido testigo de la muerte de Sosa y que luego dejó el grupo y logró volver por su cuenta a Portugal. Al encontrarse de vuelta en su patria, explica el hombre, les contó a los parientes de Sosa sobre la «enamorada muerte» de aquel, y concluye diciendo: «Creyéronla y, aunque yo no se la afirmara de vista, la creyeran, por tener casi en costumbre el morir de amores los portugueses» (436).

En este punto de la novela, los lectores se enteran de dos consecuencias significativas de la muerte de Sosa, la una evidente y la otra sugerida: primero, su hermano le ha celebrado un segundo funeral y, a falta del cadáver, había situado en la capilla familiar una piedra de mármol que hiciera de sepultura. Sobre aquella piedra, el hermano ha puesto un epitafio «discreto y gracioso», así en palabras del portugués, que valdría la pena leer; segundo, pocos días después de saber de la muerte de Sosa, Leonora, su novia ya monja, había fallecido, posiblemente a causa de la trágica noticia.

Un examen atento del episodio en cuestión revela que la historia de Manuel de Sosa Coitiño está plagada de falsedades: falso es su matrimonio con Leonora, que se enmascaró como un matrimonio humano para revelarse ulteriormente como una boda mística. Recordemos a este respecto el empleo particular de la palabra «teatro» para designar la tribuna, empleo que sugiere que el casamiento no fue más que una función teatral ${ }^{4}$; falsa es también la

3. «Con más breves razones de las que sean posibles daré fin a mi cuento con darle al de mi vida, si es que tengo de dar crédito a cierto sueño que la pasada noche me turbó el alma» (199).

4. La palabra «teatro» aparece tres veces en el episodio en cuestión, enmarcando llamativamente el «espectáculo público de la religiosidad de Leonor» (Armstrong-Roche 2011: 23). En la edición utilizada para el presente trabajo, Romero Muñoz pone al pie de su primera ocurrencia la nota siguien- 
sepultura hecha por su hermano en Lisboa, debajo de la cual no yace ningún cadáver; finalmente, como veremos a continuación, falso es el epitafio puesto sobre aquella sepultura, un epitafio que pretende enterrar a Sosa (física y simbólicamente) en el lugar común del portugués muerto de amor:

Aquí yace viva la memoria del ya muerto Manuel de Sosa Coitiño, caballero portugués, que, a no ser portugués, aún fuera vivo. No murió a las manos de ningún castellano, sino a las del amor, que todo lo puede. Procura saber su vida y envidiarás su muerte, pasajero (437).

Según el epitafio que marca su sepultura, Manuel de Sosa Coitiño murió de amor por el hecho de ser portugués. Esta conexión entre ser portugués y estar locamente enamorado no era excepcional en los tiempos de Cervantes. Por el contrario: según Miguel Herrero García, autor del libro Ideas de los españoles del siglo XVII, la mentalidad española de la época captaba la pasión amorosa como una cualidad propia de los hijos de aquella nación. Las expresiones de este estereotipo abundan en la literatura y en el teatro del Siglo de Oro español, que han hecho del enamorado portugués, así en palabras de Herrero García, un verdadero tópico (1966: 167-178). De los varios ejemplos que ofrece el estudioso a este fenómeno socio-literario, mencionaré tres.

En El vergonzoso en palacio de Tirso de Molina, durante un diálogo entre don Antonio y doña Juana, esta última emite unos versos que alaban el amor portugués dándole la ventaja sobre el castellano:

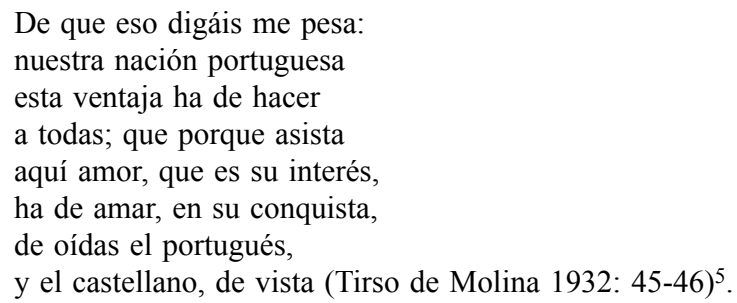

te: «teatro = 'tribuna, tablado'. Cfr. RM: V, 132, y VIII, 178» (203). Escribiendo el Persiles, Cervantes utilizaba la palabra con dicho sentido también en otros momentos, como por ejemplo en el episodio del rey Policarpo, donde el «teatro» funciona como plataforma de espectadores (266), y también, nuevamente como tribuna de desposorio, en la doble boda de los pescadores (346). No obstante, El Tesoro de la lengua castellana o española de Covarrubias no registra aquel significado, lo que me lleva a conjeturar que se trata de un uso cervantino particular. La comparación del presente episodio con la boda de los pescadores resulta especialmente interesante: en ambos, lo teatral y lo divino se conjugan para producir un giro en el curso de un desposorio. Mientras que en el episodio de los pescadores dicha combinación contribuye a su final feliz (Auristela, actuando como una especie de divinidad, enmienda los dos matrimonios trocándolos), el episodio del enamorado portugués concluye trágicamente.

5. El amor portugués es un tópico central en la obra de Tirso de Molina. Ver Pedrosa (2007) y Palomo (1999). 
El segundo ejemplo proviene de Reinar después de morir de Luis Vélez de Guevara. Frente al discurso amoroso de su príncipe, el criado Brito exclama: «iQué amor tan de Portugal!» (Vélez de Guevara 1948: 75).

Finalmente, sería de interés considerar el fragmento siguiente de Santo Negro Rosambuco de Lope de Vega, el cual ilustra el amor portugués mediante la metáfora del derretimiento:

LAURA. ¡Qué lisonjero venís!

MOLINA. No es lisonja; que amor es.

LAURA. Debéis de ser portugués,

Pues tan pronto os derretís (Lope de Vega 1894: 363).

En un trabajo más reciente dedicado a las representaciones de los portugueses en el imaginario colectivo y en la literatura del Siglo de Oro español, José Manuel Pedrosa (2007) reafirma lo postulado por Herrero García y lo desarrolla. En su opinión, el enamorado portugués no ha sido únicamente un tópico central para la cultura y la literatura españolas de aquella época sino quizá el más común de todos los estereotipos relativos a los portugueses (otros serán la arrogancia, su valor, su anti-castellanismo, su asociación con lo judío y lo converso, etc.).

Pedrosa hace su propio recorrido literario en busca del enamorado portugués, ofreciendo ejemplos complementarios a los de Herrero García y extraídos de la novela pastoril, la canción tradicional, los refranes, el teatro y más. Con el paso del tiempo, explica el investigador, a aquel tópico fueron agregándose «variantes y desarrollos», es decir, una suerte de sub-tópicos que empezaban a acompañar y caracterizar la representación literaria del enamorado portugués. Entre estos, Pedrosa menciona la edad temprana, la afición hacia la música y el canto, y la locura.

Como ejemplo de la «adolescente precocidad» de los enamorados portugueses, Pedrosa rescata la canción tradicional de la portuguesilla: «Que arrojóme la portuguesilla / narangitas de su naranjal, / que arrojómelas y arrojéselas / y bolviómelas a arrojar» (Pedrosa 2007: 102, citado en Frenk 2003). Con respecto a la asociación con el canto y la locura, cabe mencionar un pasaje de Carta ridícula de Diego Monfar, en el que Pedrosa encuentra una confluencia de estas dos variantes:

\footnotetext{
El rey de Portugal dicen que vive, y se han holgado tanto los portugueses de esta buena nueva, que todos andan locos y enamorados; brincan y folixan $y$ cantan mil cantinas, y ya no se acuerdan de la pérdida de la nao cuando duermen (Pedrosa 2007: 106, citado en Paz y Meliá 1964: 169-171).
}

Además de los casos mencionados por Herrero García y Pedrosa, quisiera aportar otros dos ejemplos emblemáticos de la manifestación del enamorado portugués en las letras áureas. La primera proviene de La vida del Buscón de Francisco de Quevedo. En el curso de sus andanzas, Pablos, el protagonista de la obra, se encuentra con un tal portugués. Es importante que reconozcamos 
tanto la crueldad con la que el texto construye el personaje como la acumulación de varios estereotipos y lugares comunes relativos a los portugueses: el amor desmesurado, las botas portuguesas, el canto, la valentía ridiculizada y la arrogancia.

El portugués se llamaba o senhor Vasco de Meneses, caballero de la carti1la, digo de Christus. Traía su capa de luto, botas, cuello pequeño y mostachos grandes. Ardía por doña Berenguela de Robledo, que así se llamaba. Enamorábala sentándose a conversación, y suspirando más que beata en sermón de Cuaresma. Cantaba mal, y siempre andaba apuntado con él el catalán, el cual era la criatura más triste y miserable que Dios crió. Comía a tercianas, de tres a tres días, y el pan tan duro, que apenas le pudiera morder un maldiciente. Pretendía por lo bravo, y si no era el poner güevos, no le faltaba otra cosa para ser gallina, porque cacareaba notablemente (Quevedo 2006: 251-252).

El segundo ejemplo pertenece a otra comedia de Lope de Vega, titulada El príncipe perfecto (primera parte). Esta obra contiene varias manifestaciones del enamorado portugués; las citaré según el orden de su aparición en el texto:

DOÑA LEONOR. Por alevoso a mis verdades.

Este pienso que es bueno.

«Si de mi pura fe te persüades...»

(Lee.)

No quiero persuadirme,

si no es saber que no hay ausente firme.

Veamos ésta. ¡Ay cielo!

(Lee.)

«Yo me muero de amor, Leonor me abrasa, ángel de puro hielo...»

¡Qué derretido portugués! (Lope de Vega 1955: 1109).

DOÑA LEONOR. [...]

No pude yo defenderme, portugués del alma mía, de tu amorosa porfía, tan cerca de verte y verme.

Huésped, pudiste vencerme (Lope de Vega 1955: 1119).

DON JUAN. Nació amor en Portugal:

no llevo allá cosa nueva (Lope de Vega 1955: 1119)6.

6. Para una lectura adicional sobre el enamorado portugués en las letras españolas, ver los estudios de Weber de Kurlat (1971) y Diago (1991). 
Los casos anteriormente examinados ejemplifican la popularidad de la que gozaba el tópico del «enamorado portugués» y sus tres sub-tópicos en las letras españolas del Siglo de Oro. Cabe ahora preguntarnos si nuestro portugués cervantino cumple en rigor con aquel estereotipo. En opinión de Pedrosa, la respuesta es positiva: «Es muy probable que Los trabajos de Persiles y Segismunda, de Cervantes, sea la obra que mejor reflejó -con hábil mezcla de pasión melodramática y de sutil ironía- el tópico del portugués enamorado en la España de los Siglos de Oro» (2007: 101). Esta es también la opinión general de los críticos que han abordado el tema. Sin embargo, poca atención ha sido otorgada al modo en que el episodio termina subvirtiendo aquel estereotipo. El presente estudio, como se verá a continuación, intenta suplir esta ausencia en la crítica cervantina.

Un examen del episodio en cuestión parece demostrar que Manuel de Sosa Coitiño cumple con todos los sub-tópicos correspondientes al enamorado portugués. En primer término, tanto Sosa como Leonora se encuentran en una edad significativamente temprana: la adolescencia de Leonora aparece de modo explícito en el texto cuando su padre dice que es demasiado joven para ser desposada, y nos enteramos de la temprana edad de Sosa cuando él mismo, hablando de su novia, señala que «ni en el linaje, ni en la hacienda, ni aun en la edad, diferenciábamos en nada» (200).

Con relación a las dotes musicales, es dable afirmar que este sub-tópico caracteriza a Sosa en gran medida desde su primera aparición en el texto. Recordemos que Periandro y Auristela notan la presencia del soldado por su canto en la barca, y que desde ese momento y hasta que Sosa comienza a relatar su historia, el narrador y los personajes se refieren a él reiteradamente como «el músico» y «el cantor».

Finalmente, la locura de Sosa se manifiesta abiertamente al término del fracasado desposorio: una vez que Leonora declara que se ha casado con Jesucristo y se convertirá en una monja, el portugués vuelve a su casa y ahí, poco a poco, va perdiendo el juicio.

Ciertamente, Sosa refleja a la perfección aquellos tres sub-tópicos señalados y ejemplificados por Pedrosa: irrumpe en la trama con su soneto, es tan joven como su deseada Leonora, y su canto de cisne es un canto de demencia a raíz de aquel «triste y no imaginado suceso» (205). Pero, con todo, a mi juicio Sosa no llega a cumplir con el tópico más importante del enamorado portugués: el hecho de estar enamorado.

Según Pedrosa, el tópico del enamorado portugués consiste en su condición de rendido y desesperado enamorado, propenso a la enfermedad y aun a la muerte por amor (2007); en mi opinión, el episodio de Manuel de Sosa Coitiño podrá ser un cuento de locura y de muerte, pero no de amor. Un examen atento del texto cervantino revela que a lo largo de su narración en el capítulo I, 10, Sosa nunca se refiere a su novia en términos amorosos o afectivos; en ningún lugar en su discurso dice que quiere a Leonora ni mucho menos que está enamorado de ella. Más bien, tal como señala Ruth El Saffar, el soldado habla de su novia en términos claros de deificación: «Manuel's 
problem was deifying the young woman he loved. So exalted was Leonora in Manuel's imagination that he dared not even approach her» (1984: 136); «Manuel Sosa de Coitiño [...] representa al hombre espiritual por excelencia que concibe a la mujer como algo digno de veneración [...] Repite una y otra vez que es más digna de ser adorada que desposada» (1979: 231-232). Antonio Gargano sigue esta línea interpretativa, identificando el pecado de Sosa con la idolatría: «En la mente y en el corazón de Manuel [Leonora] toma el lugar de aquel que para el hombre debería ser el único objeto de adoración, Dios») (2001: 125).

El proceso de la deificación de Leonora - no del amor hacia ella- es el que caracteriza la vida del soldado portugués. Este proceso comienza cuando Sosa pasa su tiempo observando, o mejor dicho espiando obsesivamente a su deseada doncella, y culmina en el altar teatral de la iglesia, donde Leonora le dirige la palabra por primera vez, solo para confesar su mística traición. Durante este tiempo, no encontramos una verdadera interacción entre los dos personajes, sino solo gestos de adoración y sentimientos de inferioridad por parte de Sosa: luego de aceptar la postergación de la boda en dos años, Sosa confiesa que no ha dejado de servir públicamente a su deseada joven; en el día de su partida a Berbería, cuando se encuentra por primera vez con Leonora, queda mudo y atónito ante su hermosura. Estimo que el diálogo constituye una condición esencial para cualquier contacto humano, más aún para las relaciones amorosas; en el episodio en cuestión, como bien ha notado Armstrong-Roche (2011), las relaciones entre Sosa y Leonora no están basadas en el diálogo sino en el silencio, en la incomunicación.

La deificación de Leonora culmina el día de la boda; es ahí donde encontramos las expresiones más contundentes de su veneración, y donde se evidencia la pertinencia de los postulados de El Saffar y Gargano: frente a la apariencia deslumbrante de la novia Leonora, Sosa solo puede confesar, «me hallé indigno de merecerla, por parecerme que la agraviaba, aunque yo fuera el emperador del mundo» (203); cuando la doncella sube al altar-teatro, el soldado, todavía abajo y en perfecta posición de adoración religiosa, la describe con un imaginario que evoca las antiguas y crueles deidades: «Pareció a todos los ojos que la miraban lo que suele parecer la bella aurora al despuntar del día, o lo que dicen las antiguas fábulas que parecía la casta Diana en los bosques» $(203)^{7}$. Sosa no solo habla en términos de deificación sino que la lleva a la práctica, arrodillándose dos veces frente a Leonora durante la ceremonia del casamiento: una vez después de subir al altar, y otra vez justo antes de bajar de aquel. Si las recurrencias de la palabra «teatro»son las que otorgan al desposorio su marco de artificio y de engaño, el acto de caer de rodillas aporta otro marco, correspondiente al culto y a la adoración.

7. «Al acecho en las sombras arquetípicas de Leonor se encuentra la cazadora casta y fría, la Diana de las Metamorfosis de Ovidio, azote de Acteón, el cazador desventurado que paga con su vida la mirada fortuita a la diosa [...] Leonor se asocia así tanto con la belleza como con la muerte» (Armstrong-Roche 2011: 22-23). 
La única vez en toda la obra que Sosa pronuncia la palabra «amor» se encuentra en el capítulo I, 9, cuando el soldado canta su soneto al golpe de los remos en pleno mar:

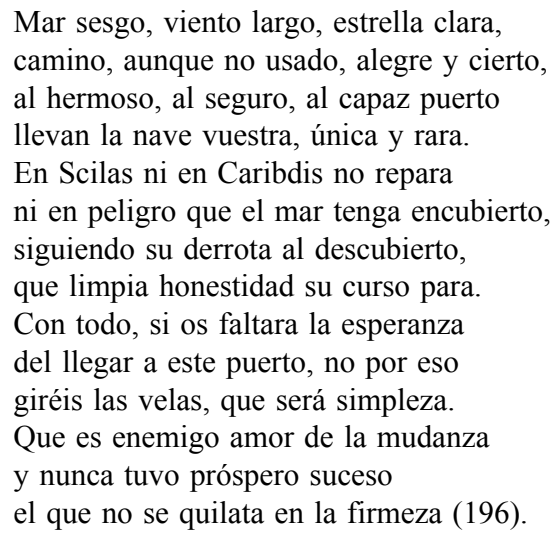

Aparentemente, se trata de un soneto apasionado que Sosa canta para expresar su amor por Leonora; Periandro y Auristela así lo interpretan y su convicción nos induce a aceptar inmediatamente esta lectura. No obstante, tal como demuestra Isabel Lozano-Renieblas (2004), un examen pormenorizado de la composición poética revelará una perspectiva distinta. Según la investigadora, el poema cervantino introduce una serie de metáforas tópicas de la tradición de la lírica amorosa como la nave de amor, el amante-navegante, la tempestad y el puerto seguro, entre otras, solo para alterar su significado tradicional y otorgarles uno nuevo. En sus palabras, «La construcción del poema se efectúa, en efecto, no sobre imágenes centrales sino sobre variaciones. El autor toma como modelo el imaginario de la metáfora náutica de la lírica petrarquista pero le da un nuevo sentido al acomodarlo al nuevo contenido temático del soneto» (Lozano-Renieblas 2004: 302).

De este modo, mientras que la imagen de la nave simboliza tradicionalmente el alma del enamorado, en el soneto cervantino esta designa a la dama, Leonora; por su parte, el viaje marítimo, que hubiera significado la aventura amorosa del hablante lírico-amante, toma en el soneto la forma de la peregrinación de Leonora hacia el amor de Dios; los tópicos del mar turbulento, el viento y las rocas de Escila y Caribdis -elementos cuya función tradicional es la de obstaculizar el viaje- están ausentes o contribuyen a su final feliz; finalmente, el puerto seguro, que hubiera representado el fin de las vicisitudes de la aventura amorosa, termina evocando la figura de Cristo, el esposo místico de Leonora. "En efecto», concluye la investigadora, "el soneto no propone un pathos lírico. No hay una retórica de sublimación de la amada. Ni siquiera la voz lírica remite a la pasión o el sentimiento del poeta. Manuel de Sosa no está cantando al amor de Leonora sino al amor que Leonora siente por Cristo» (2004: 305). 
Los personajes que encarnan el tópico del enamorado portugués vivirán y morirán bajo la insignia del amor. En cambio, la vida de Sosa carece de este elemento tan fundamental en la construcción del estereotipo. Este es también el caso respecto de su muerte. Tal como el propio soldado admite al término de su historia, no fue el amor lo que lo habría de matar sino el imaginar compulsivamente lo sucedido en el monasterio, una imaginación que casi lo llevó al borde de la locura: "Y, diciendo esto, me bajé del teatro y, acompañado de mis amigos, me volví a mi casa, adonde, yendo y viniendo con la imaginación en este estraño suceso, vine casi a perder el juicio $\mathrm{y}$, ahora, por la misma causa, vengo a perder la vida» (205).

El análisis efectuado anteriormente conduce a una reevaluación del episodio del enamorado portugués: Manuel de Sosa Coitiño no murió por haber amado a Leonora (según estimo, nunca la amó), sino por haberse sometido a un proceso delirante de deificación que termina de un modo trágico e inexplicable. Pese a ello, parece que las instancias narrativas y muchos personajes en el Persiles se obstinan en referirse a la pareja una y otra vez como enamorados.

En este sentido, una vez que entendemos el proceso de deificación, es posible observar un proceso paralelo: se trata de aquellos intentos reiterados del narrador y de los personajes de la obra de «corregir» este supuesto error en el tópico del enamorado portugués y, finalmente, enterrar al soldado en el lugar común del portugués muerto de amor.

Este proceso se inicia después de los comienzos del proceso de deificación, en la primera ocasión que los personajes del Persiles califican a Sosa de enamorado. Reexaminando el episodio desde el nivel de la historia (fabula), podríamos identificar dicho momento en la ceremonia de la boda; es ahí donde los muchos invitados felicitan a la pareja pronunciando repetidamente la palabra «amor» con sus variaciones: «Vivid felices y luengos años en el mundo, ¡oh, dichosos y bellísimos amantes! Coronen presto hermosísimos hijos vuestra mesa y, a largo andar, se dilate vuestro amor en vuestros nietos» (204).

El proceso prosigue cuando los protagonistas, después de dejar atrás la isla bárbara, reparan en el canto de Sosa. Mientras que Ricla lo tilda de ocioso, Periandro y Auristela lo consideran enamorado. Es importante notar que no solo son los personajes quienes califican a Sosa una y otra vez de enamorado sino también las instancias narrativas: una vez en el título del capítulo I, 10, «De lo que contó el enamorado portugués» (199), y otra en el capítulo III, 1: «En otra parte estaba la isla nevada, donde el enamorado portugués perdió la vida» (438). Pero sigamos examinando el fenómeno desde el nivel de los personajes.

Hasta la muerte de Manuel de Sosa Coitiño, el proceso de su construcción en base al estereotipo del enamorado portugués es esporádico y limitado en extensión, tanto por parte de los constructores como por la del objeto de dicha construcción. En efecto, son apenas dos individuos (Periandro y Auristela) y un grupo grande pero impersonal (los invitados al casamiento) quienes inten- 
tan caracterizar a Sosa según dicho tópico. Sin embargo, luego de su muerte, y en particular desde que los protagonistas arriban a Portugal, este fenómeno adquirirá una clara dimensión social.

Respecto del objeto de la construcción, este pasa de ser un individuo particular a simbolizar a todo un grupo social. Ello ocurre cuando Antonio el bárbaro, al acercarse a Lisboa, exclama:

Aquí el amor y la honestidad se dan las manos y se pasean juntos, la cortesía no deja que se le llegue la arrogancia y la braveza no consiente que se le acerque la cobardía. Todos sus moradores son agradables, son corteses, son liberales y son enamorados, porque son discretos (432).

En lo que atañe al número de constructores de Sosa como estereotipo, la conversación que Periandro ha mantenido con el anónimo portugués revela que su cantidad es mucho mayor de lo que se pensaba:
Halléme a la muerte de Manuel de Sosa Coitiño, el caballero portugués [...] Trújome la buena suerte a mi patria; conté aquí a sus parientes la enamo- rada muerte; creyéronla y, aunque yo no se la afirmara de vista, la creyeran, por tener casi en costumbre el morir de amores los portugueses (436).

En primer lugar, aquel hombre portugués que ha asistido a la muerte de Sosa ha convertido dicha muerte en una «muerte enamorada». Luego, el portugués les contó esta historia a los parientes de Sosa, que a su vez la creyeron de inmediato. Esta instantánea unanimidad pone al descubierto que la tipificación del soldado, lejos de tener uno o varios «culpables», es llevada a cabo gracias a la complicidad de muchos personajes y tal vez de toda una sociedad afectada por el mal de la categorización.

Desde esta perspectiva, los portugueses del Persiles parecen ser tanto los constructores del tópico del enamorado portugués como los objetos de esta construcción. No obstante, a partir de estudios como el de Herrero García, Pedrosa y otros, sabemos con seguridad que dicho tópico formaba parte de la representación de los portugueses en el imaginario colectivo de los españoles. Por lo tanto, aunque en el episodio cervantino la sociedad portuguesa parezca víctima y victimaria a la vez, en mi opinión se trata solo de un irónico disfraz configurado por Cervantes, siendo la sociedad española de su tiempo aquella que constituía el verdadero blanco de su crítica. De este modo, tanto Antonio el español como el anónimo portugués y los parientes de Sosa son, de hecho, voceros implícitos de la mentalidad española de aquel tiempo y de su visión reductiva del pueblo portugués.

En su libro sobre el Quijote, Ruth Fine señala una particularidad de la poética de caracterización de personajes inscripta en la obra. Se trata del fenómeno en cuyo marco el personaje cervantino va siendo caracterizado simultáneamente por una multiplicidad de constructores en el texto: las voces narrativas, los otros personajes, y el mismo personaje en cuestión, quien procura construirse a sí mismo (2006: 81-111). Son muchos los personajes 
cervantinos que pasan sus vidas autocreándose junto con y a pesar de sus constructores: desde personajes protagónicos como don Quijote y Sancho Panza hasta personajes secundarios como el morisco Ricote y la muchacha asturiana Maritornes. Como la pluralidad de caracterizaciones de un personaje resulta a menudo conflictiva, los caracteres cervantinos se sostienen en una permanente tensión constructiva. Según Fine, podríamos entender esta tensión como un choque entre el método directo e indirecto de caracterización, y el desplazamiento del primero por el segundo ${ }^{8}$. Para profundizar en el fenómeno y en su relevancia para el episodio del enamorado portugués, considero oportuno revisar el caso de Maritornes ${ }^{9}$.

Según demuestra el examen de Fine, a lo largo del Quijote y en especial en el capítulo I, 16, la voz narrativa y algunos personajes de la obra construyen a Maritornes de un modo bastante negativo: el narrador la caracteriza como una criatura deforme, repugnante, ignorante y pecadora; don Quijote la vuelve en objeto de sus fantasías caballerescas y la involucra en una escena humillante en la noche de la venta; finalmente, el arriero la denigra abiertamente, llamándola puta. No obstante, la muchacha asturiana logra desmentir estas malévolas caracterizaciones: en el capítulo I, 17, ella aparece como buena y compasiva cristiana cuando brinda agua fría y después vino al recién manteado Sancho; su discurso en el capítulo I, 32, revela que no es tan desentendida en historias de caballerías como la voz narrativa intentaba destacar; finalmente, Maritornes consigue vengarse de don Quijote en el capítulo I, 43, convirtiéndolo en la víctima de sus propias fantasías eróticas.

Maritornes, determina Fine, es un personaje victimizado por sus diversos constructores. Pese a ello, la muchacha asturiana logra desasir sus manos y auto-caracterizarse como un ser compasivo e inteligente. La antes mencionada tensión entre el método directo e indirecto de caracterización es evidente: mientras que la voz narrativa, don Quijote y el arriero, procuran construir a Maritornes definiéndola a su antojo, la asturiana desafía estas caracterizaciones directas mediante los modos indirectos de caracterización, es decir, mediante sus propios actos y sus palabras. «La fea y tonta asturiana», concluye Fine, «ha transgredido los límites del estereotipo extratextual y, desde ya, del género sexual, logrando dignificarse como construcción autónoma» (2006: 108).

En el Quijote desfilan, así como Maritornes, un sinnúmero de personajes tópicos que Cervantes logra desestabilizar. El bandolero catalán Roque Guinart, las ricas villanas como Dorotea, y la nobleza representada en la obra, son solo algunos ejemplos de ello.

8. El método directo de caracterización consiste en la definición del personaje por parte de la voz narrativa o por parte de los otros personajes. En cambio, el método indirecto de caracterización consiste en los modos en que el personaje se auto-caracteriza, principalmente mediante su discurso y sus acciones (Ewen 1971).

9. Esta no será la primera comparación de Sosa con un personaje del Quijote. Ver el análisis iluminador que efectúa Armstrong-Roche (2011) en torno a las similitudes entre el soldado portugués y el pastor-poeta Grisóstomo. 
En mi opinión, el caso de Manuel de Sosa Coitiño es esencialmente paralelo al de Maritornes: al igual que esta, Sosa es víctima de una multiplicidad de constructores - la voz narrativa y muchos de los personajes del Persilesque procuran encasillarlo en un estereotipo socio-literario que no le corresponde. Pese a esta afinidad fundamental, los dos casos exhiben varias diferencias significativas.

En primer término, la cantidad de constructores en el caso de Sosa es mucho mayor que en el de Maritornes. Si en el caso de esta última se trata de tres constructores principales - la voz narrativa, don Quijote y el arrierolos constructores de Sosa son una verdadera multitud: desde la voz narrativa y los personajes protagónicos de Periandro y Auristela, hasta los muchos invitados a la ceremonia de casamiento, el hombre portugués, los parientes de Sosa y su propio hermano. Además, como se ha dicho anteriormente, es posible que los constructores de Sosa constituyan la totalidad de la sociedad portuguesa (es decir, una proyección enmascarada de la española).

En segundo término, mientras que la caracterización de Maritornes es de relativa diversidad, la de Sosa es totalmente unívoca. Si bien los constructores de la muchacha siempre la caracterizan negativamente, esta negatividad cobra muchas formas (deformidad corporal, baja inteligencia, promiscuidad, etc.); en cambio, la legión de constructores de Sosa coincide unánimemente en su caracterización reiterada como un enamorado.

Finalmente, mientras que Maritornes logra escapar de su estereotipo de sirvienta despreciable y auto-crearse pese a sus constructores, el soldado, mucho más pasivo que ella, no lo consigue. Más aún, los constructores de Sosa, encabezados por su propia familia, terminan enterrándolo dentro de aquella sepultura simbólica y debajo de aquel dudoso epitafio.

Esta es la culminación del proceso de construcción de Sosa como el estereotipo del enamorado portugués: el epitafio que ridiculiza su muerte por amor. A la luz de lo expuesto, la segunda sepultura de Sosa recibe un nuevo significado, doblemente falso: en primer lugar, como hemos visto, la sepultura no contiene ningún cadáver; y en segundo lugar, esta lápida representa el injusto entierro del soldado portugués en el cementerio de los estereotipos españoles. Considero que la expresión de «metáfora muerta» sería aquí muy pertinente.

Antes de concluir el presente examen, quisiera reflexionar acerca de una elipsis central en el episodio del enamorado portugués: ¿por qué Leonora trocó su casamiento terrenal con Sosa por una unión divina con Cristo? ¿Fue su decisión voluntaria el convertirse en una monja o tal vez se vio obligada a tomar aquel camino? Y, finalmente, ¿por qué decidió hacerlo de un modo tan abrupto y cruel, fingiendo un desposorio terrenal?

Stanislav Zimic (2005) cree que la elección de Leonora deriva de una religiosidad auténtica. Según El Saffar (1984), el problema se origina tanto en la deificación de Leonora por parte de Sosa como en la autopercepción de sí misma como mujer a quien ningún hombre puede igualar. Encarcelada en este paradigma, Leonora opta por tomar los hábitos el día de su boda. Final- 
mente, Armstrong-Roche (2011) coincide con El Saffar en que la novia eligió la vida monástica como vía de escapatoria, pero no de sí misma sino de un casamiento impuesto por su padre:

Leonor, por lo tanto, elude una autoridad paternal (la de su padre) refugiándose bajo otra (la de Dios), contraponiendo la vocación religiosa con un sacramento (el matrimonio), y eligiendo un esposo divino (Cristo) sobre otro humano (Sosa) -elecciones que le permiten a la vez ser obediente y salirse con la suya (2011: 26-27).

En mi opinión, cada una de estas tres interpretaciones es válida y admisible. No obstante, al negarnos un acceso a la interioridad de Leonora (y de hecho a la de cualquiera de los actores de este episodio, a excepción de Sosa), el texto resiste una lectura conclusiva. Nosotros, como lectores del episodio, nunca podremos saber con certeza por qué Leonora ha actuado del modo en que lo hizo, y sin embargo debemos aceptar las trágicas consecuencias de su elección. Esta incertidumbre, inherente al episodio en cuestión, hace que su recepción sea aún más trágica.

Además de los motivos de la decisión de Leonora, los cuales considero como el blanco principal de esta historia, el episodio del enamorado portugués presenta una serie de problemas insolubles: ¿cómo fue posible que Sosa, siendo muy joven, ejerciera el cargo de capitán general en las fuerzas portuguesas? Concluido el tiempo de espera, ¿quiénes eran los que avisaron a Sosa de la celebración del casamiento? ¿En qué punto decidió Leonora tomar los hábitos? ¿Cuál era el grado de complicidad de la Iglesia con el acto? ¿Cuál fue la reacción de su padre? ¿Por qué el texto se detiene en el hecho de que Periandro no reconozca al anónimo portugués? ¿Cuál fue la verdadera causa de la muerte de Leonora? ¿Cómo llegó Sosa a estar cautivo en la isla de los bárbaros?

Sabemos que la presencia de blancos en las obras literarias es no solo frecuente, sino necesaria. Gracias a ellos, al finalizar la lectura de un texto, a menudo experimentamos, en mayor o menor medida, una sensación de incertidumbre y de ambigüedad. No obstante, estimo que en virtud de la inusual cantidad -y de la centralidad- de los blancos irresueltos configurados en este episodio, claramente se manifiesta aquí una intentio operis cuyo rasgo distintivo es una pronunciada e inherente indecidibilidad, lo cual se traduce en la imposibilidad de establecer una interpretación conclusiva del episodio ${ }^{10}$.

En el presente estudio hemos observado los modos en que la obra cervantina construye el personaje de Manuel de Sosa Coitiño según el lugar común del enamorado portugués, uno de los tópicos más populares de las letras españolas del Siglo de Oro. A pesar de haber otorgado al soldado muchos de los rasgos característicos de dicho estereotipo - la edad temprana, las dotes

10. Aldo Ruffinatto (2004) reconoce esta calidad de «no-acabado» del episodio del enamorado portugués y compara su inconcluso final con el de la obra entera. 
musicales y la locura-, el texto ha dejado de lado un elemento esencial: el amor. Más aún, en el curso del episodio la voz narrativa y los personajes procuran suplir aquella carencia calificando a Sosa una y otra vez de enamorado, enterrándolo finalmente en la manifestación más extrema del tópico, la del portugués muerto de amor.

Según he intentado demostrar, todas estas estrategias constructivas, contrarias en apariencia, operan conforme a la misma intencionalidad textual. Cervantes ha recreado al enamorado portugués omitiendo intencionalmente el elemento central del amor con el fin de desestabilizar dicho tópico, y la mencionada insistencia de los personajes en calificar al soldado de enamorado funciona como un indicio irónico de aquella subversión.

Sosa, como ya fuera señalado, emerge como un personaje eminentemente pasivo en este contexto. En lugar de escapar de sus constructores y autocrearse de un modo independiente - tal como había logrado Maritornes- el soldado cumple silenciosamente con su «muerte enamorada» sin poner ninguna objeción. Es por lo tanto la responsabilidad del lector, a través de una lectura atenta del texto, el identificar los indicios y las ironías, desenterrar a Sosa de su injusta sepultura y revelar el significado subversivo del episodio. Desde esta perspectiva, el epitafio del soldado portugués puede ser leído no solo como la imposición de un estereotipo, sino como un llamado implícito dirigido al receptor del texto a «procurar saber» la vida de Manuel de Sosa Coitiño.

En su libro sobre el Persiles, Joaquín Casalduero percibe el soneto de Sosa como un momento textual que cristaliza el sentido de la obra entera ${ }^{11}$. A diferencia de la lectura más bien alegórica que realiza el estudioso, me importa subrayar los alcances metaliterarios de esta observación: en mi opinión, aquella composición sintetiza en gran medida el quehacer narrativo de Cervantes, su poética de subversión y transgresión que recorre todos los niveles de su obra. Según hemos señalado, el autor español introduce en el poema una serie de metáforas tópicas de la tradición petrarquista solo para alterar su significado tradicional y brindarles uno nuevo. Del mismo modo, en el episodio en cuestión, Cervantes ha elegido presentar y desarrollar el tópico del enamorado portugués para subvertirlo después, criticando a toda una sociedad en el proceso.

Es dable argumentar que los tópicos relativos a los portugueses de las letras españolas del Siglo de Oro son falsos y engañosos; lo comprueba el hecho de que muchos de estos estereotipos habían sido y seguirían siendo utilizados arbitrariamente en otros lugares y tiempos, contra una diversidad de naciones y pueblos. Por consiguiente, cabe percibir el episodio aquí analizado, así como muchos otros momentos de la obra cervantina, como complejas dramatizaciones que ponen en tela de juicio estos estereotipos, develando, a «quien bien lo mire», su esencia reductiva y su falsedad.

11. «En la nave de la vida, por el mar del mundo, guiados por la honestidad, aquilatarse en la firmeza y la lealtad, que nos conduce al puerto quieto» (Casalduero 1975: 46). 


\section{BIBLIOGRAFÍA CITADA}

Armstrong-Roche, Michael (2011). «Un replanteamiento paradoxográfico de la ortodoxia religiosa, política y social en Cervantes: el mito gótico y el episodio de Sosa y Leonor en el Persiles», en Carmen Rivero Iglesias (ed.), Ortodoxia y heterodoxia en Cervantes. Alcalá de Henares: Centro de Estudios Cervantinos, pp. 15-32.

Azar, Inés (1998). «Turns of Enchantment: Imagining the Real in Don Quixote», Cervantes. XVIII (2), pp. 14-25.

Casalduero, Joaquín (1975). Sentido y Forma de «Los Trabajos de Persiles y Sigismunda». Madrid: Gredos.

Cervantes, Miguel de (2004). Los trabajos de Persiles y Sigismunda, ed. Carlos Romero Muñoz. Madrid: Cátedra.

Diago, Manuel V. (1991). «Una máscara del teatro renacentista: el "portugués enamorado", de las orillas del Tajo a las riberas del Plata», Criticón. 51, pp. 43-49.

El Saffar, Ruth (1979). «Tres imáges claves de lo femenino en el Persiles», Revista Canadiense de Estudios Hispánicos. III (3), pp. 219-236.

El Saffar, Ruth (1984). Beyond Fiction. The Recovery of the Feminine in the Novels of Cervantes. Berkeley \& Los Angeles: University of California Press.

Ewen, Josef (1971). «La teoría del personaje en literatura», Hasifrut. 3, pp. 1-29 [en hebreo].

Fine, Ruth (2006). Una lectura semiótico-narratológica del Quijote en el contexto del Siglo de Oro español. Madrid - Frankfurt: Iberoamericana - Vervuert.

Frenk, Margit (2003). Nuevo Corpus de la antigua lírica popular hispánica (siglos XV a $X V I I)$. México D. F.: Fondo de Cultura Económica.

Gargano, Antonio (2001). «Contra la "concepción progresiva de la historia": barbarie y civilización en los primeros capítulos del Persiles», en Alicia Villar Lecumberri (ed.), Cervantes en Italia (Actas del X Coloquio Internacional de la Asociación de Cervantistas). Palma de Mallorca: Asociación de Cervantistas, pp. 121-127.

Herrero García, Miguel (1966). Ideas de los españoles del siglo XVII. Madrid: Gredos.

Hutton, Lewis J. (1981). «El enamorado portugués del Persiles de Cervantes», en Manuel Criado de Val (dir.), Cervantes, su obra y su mundo: Actas del I Congreso Internacional sobre Cervantes. Madrid: EDI-6, pp. 465-469.

Lozano-Renieblas, Isabel (2004). «"Mar sesgo, viento largo, estrella clara” o la metáfora de la nave de amor en el Persiles», Anales Cervantinos. XXXVI, pp. 299-308. https:// doi.org/10.3989/anacervantinos.2004.010.

Molina, Tirso de (1932). El vergonzoso en palacio, El burlador de Sevilla. Madrid: Espasa-Calpe.

Palomo, María del Pilar (1999). «El amor portugués en Tirso de Molina», en María del Pilar Palomo (ed.), Estudios tirsistas. Málaga: Universidad de Málaga, pp. 153-161.

Paz y Meliá, Antonio (ed.) (1964). Sales españolas o agudezas del ingenio nacional. Madrid: Atlas.

Pedrosa, José Manuel (2007). «El otro portugués: tipos y tópicos en la España de los siglos XVI al XVIII», Iberoamericana. VII (28), pp. 99-116.

Quevedo, Francisco de (2006). El Buscón, ed. Domingo Ynduráin. Madrid: Cátedra.

Roig, Adrien (2004). «De la vida de Manuel de Sousa Coutinho al "Triste y no imaginado suceso" del portugués que murió de amor en el Persiles», en Alicia Villar Lecumberri (ed.), Peregrinamente peregrinos: Actas del V Congreso Internacional de la Asociación de Cervantistas. Lisboa: Fundación Caluste Gulbenkian, pp. 879-898.

Ruffinatto, Aldo (2004). «El narrador agotado y los horizontes de expectativas del Persiles», en Alicia Villar Lecumberri (ed.), Peregrinamente peregrinos: Actas del V Con- 
greso internacional de la Asociación de Cervantistas. Lisboa: Fundación Caluste Gulbenkian, pp. 899-909.

Teijeiro Fuentes, Miguel Ángel (2018). «Tres amigos portugueses de Cervantes en el cautiverio argelino: Francisco de Aguiar, los hermanos Sousa Coutinho y el doctor Antonio de Sosa», en Aurelio Vargas Díaz-Toledo y José Manuel Lucía Megías (eds.), Cervantes e Portugal: História, Arte e Literatura. Oporto: Estratégias Criativas-Fundación Caluste Gulbenkian, pp. 113-137.

Vega, Lope de (1894). Santo Negro Rosambuco en Obras de Lope de Vega (Tomo IV). Madrid: Real Academia Española.

Vega, Lope de (1955). El príncipe perfecto (primera parte) en Obras escogidas de Lope Félix de Vega Carpio (Tomo III: Teatro). Madrid: Aguilar.

Vélez de Guevara, Luis (1948). Reinar después de morir y El diablo está en Cantillana. Madrid: Espasa-Calpe.

Weber de Kurlat, Frida (1971). «Acerca del portuguesismo de Diego Sánchez de Badajoz (portugueses en las farsas españolas del siglo XVI)», en A. David Kossoff y José Amor y Vázquez (eds.), Homenaje a W. L. Fichter. Estudios sobre el teatro antiguo hispánico y otros ensayos. Madrid: Castalia, pp. 785-800.

Zimic, Stanislav (2005). Cuentos y episodios del Persiles: de la isla bárbara a una apoteosis del amor humano. Pontevedra: Mirabel Editorial.

Recibido: 7 de enero de 2019

Aceptado: 23 de julio de 2019 